\title{
FLUSSER E AS DORES DO ESPAÇO: \\ A ARTICULAÇÃO DO PENSAMENTO POR MEIO DO ESPAÇO EXPOSITIVO
}

\author{
“FLUSSER E AS DORES DO ESPAÇO”: \\ THE ARTICULATION OF THINKING IN THE EXHIBITION SPACE
}

\author{
Cássia Takahashi Hosni \\ (Universidade de São Paulo) \\ cassiahosni@usp.br
}

Recibido: 16/03/2018

Aprobado: 08/06/2018

\begin{abstract}
RESUMO
A exposição Flusser e as dores do espaço, apresentada no SESC Ipiranga, São Paulo, trouxe para o espaço expositivo reflexões pertinentes a trajetória do filósofo e sua relação com a imaterialização da imagem técnica. A curadoria de Norval Baitello Junior e Camila Garcia concentrou-se em trazer o pensamento flusseriano de modo lúdico, explorando as relações com instalações artísticas, registros videográficos, documentações e eventos paralelos.

Palavras chaves: Flusser e as dores do espaço; Vilém Flusser; Exposição.
\end{abstract}

\section{ABSTRACT}

The exhibition "Flusser e as dores do espaço", presented at SESC Ipiranga, in São Paulo, draws our attention to the relevant trajectory of the philosopher and its relation to the immaterialization of the technical image. The curatorship of Norval Baitello Junior and Camila Garcia highlighted Flusserian thinking in a ludic mode, exploring relationships through artistic activities, videographic records, documentations and events.

Keywords: Flusser e as dores do espaço; Vilém Flusser; Exhibition.

\section{Apresentação}

A exposição Flusser e as dores do espaço ocorreu de 10 de outubro de 2017 a 28 de janeiro de 2018, no Serviço Social do Comércio - SESC, unidade Ipiranga, em São Paulo. Dedicada a explorar de modo lúdico o pensamento de Vilém Flusser, filósofo tcheco naturalizado brasileiro, teve a curadoria de Norval Baitello Junior e Camila Garcia. Junto à curadoria, a equipe do SESC concebeu nove espaços expositivos e uma programação paralela que envolvia aulas-caminhadas, aulas-performances, performances, cursos, apresentações artísticas.

A exposição é a segunda dedicada à produção filosófica de Flusser e foi realizada a partir da cooperação entre o Arquivo Flusser de Berlim e do Arquivo Flusser em São Paulo. A primeira exibição, Without Firm Ground - Vilém Flusser \& the Arts: an exhibition, aconteceu no ZKM Center for Art and Media, em Karlsruhe, e posteriormente na Academia de Artes de Berlim, Alemanha, em 2015. 
Para a exposição paulistana, o fio condutor escolhido foi a alegoria flusseriana da "escada da abstração" ou "escalada da abstração", em que há gradativa perda de referência espacial em relação ao homem e o mundo. Assim, de acordo com a divulgação da exposição, "para Flusser, o descer da escada reflete a operação humana na cultura, que se distancia do concreto da sua existência no mundo ao encontrar meios de apreendê-lo e representá-lo de forma cada vez mais abstrata.” Diante da perda da materialidade, em favor da imaterialidade, como escrito no texto de parede, os curadores utilizam a frase "Espaço - aqui estão as minhas dores!” para ecoar um resumo do pensamento do filósofo.

As dores do espaço de Flusser podem ser compreendidas a partir das três grandes catástrofes: a primeira catástrofe ou hominização; a segunda catástrofe ou civilização; e a terceira catástrofe, a qual estamos vivendo e que ainda não tem nome. Instigante nos modos de apresentação dos conceitos, a exposição propunha pensar a filosofia de Flusser em movimento com o espectador, junto aos diversos módulos que foram criados no SESC.

Diferentemente de um museu ou um centro cultural, as unidades do SESC são conhecidas por serem lugares em que as atividades culturais estão integradas às práticas esportivas e de lazer para o público de diferentes faixas etárias. A circulação de pessoas é intensa e não é raro ver algumas crianças correndo e brincando entre os diferentes ambientes expositivos.

Ter um primeiro contato com o pensamento flusseriano na exposição ou percorrê-la como um connaisseur dependia do intuito do espectador, na qual um dos convites era vaguear e "voltar para contemplar elementos já vistos” (Flusser, 2011, p. 22), como bem disse o filósofo sobre o olhar circular na imagem. A respeito das dores do espaço, Baitello Jr. (2005) diz que é como se fosse um "aleph borgeano”, que se desdobra em infinitas possibilidades. Propondo um possível modo de percorrer a exposição, de modo a imbricar as inúmeras leituras e percepções do espaço expositivo:

Os infinitos são os espaços do nosso entorno e os transfinitos são os (nossos) infinitos interiores. Ambos são insondáveis e enigmáticos: só nos encontramos em seus meandros quando nos perdemos em suas entranhas. Este é o único programa possível para compreender a estratégia da imagem em Flusser: perderse nos caminhos transfinitos que ele percorre. (Baitello Jr., 2005, p. 3)

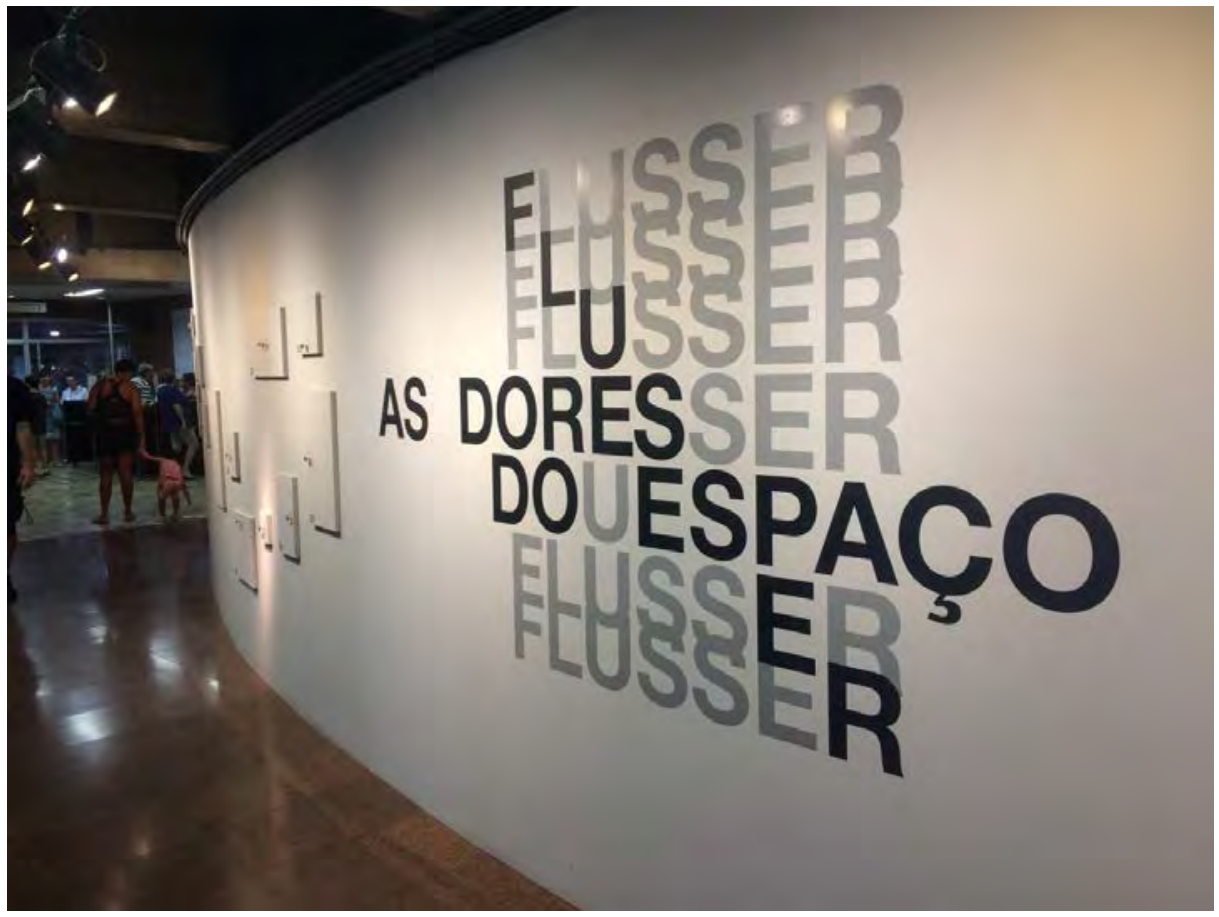

Figura 1. Entrada da Exposição. Crédito: Cássia Hosni 


\section{Sem chão}

Localizada na entrada da unidade, o primeiro módulo, "Sem chão", era constituído por pequenas portinholas e gavetas com números sustentadas no interior de uma parede em arco. A cenografia era uma introdução a biografia do filósofo e cada quadrado, retângulo, chamava o espectador para a abertura das portas de diferentes tamanhos. Cada uma das 60 portinholas abrigava fotografias, textos de jornais de sua autoria, cartas, objetos como computadores, disquetes, máquina de escrever e convites sensoriais, como uma gaveta que continha pedaços de lixa com os dizeres "sinta o exílio". Ao lado da parede, uma ficha fornecia informações sobre o significado ou a história por trás de cada objeto. No texto informativo do módulo, ressaltou-se o aspecto da vida de Flusser, partindo de Praga e permanecendo em São Paulo por 30 anos. As mudanças constantes, a falta de chão, sua consequente recusa e a desconfiança diante da pátria e das bandeiras.

Na área de convivência, foi instalado em círculo "O vento e a fuga” com vídeos, depoimentos e entrevista de Flusser com Miklós Peternák, como Imagem da televisão e espaço político à luz da revolução romena (1990); Sobre a escrita, a complexidade e a revolução técnica (1988); Sobre imagens técnicas, possibilidade, a consciência e o indivíduo (1991); Sobre religião, memória e imagem sintética (1990), em parceria com Lásló Beke). Além dos monitores/tablets, nos quais o público poderia assistir a fala de Flusser, havia cabines com obras que possuíam interferências na imagem, utilizando sobreposições de vídeos, fotos, sons e a escrita. $\mathrm{O}$ aspecto cênico do módulo envolvia uma leve cortina que sobrevoava pelo espaço. Como no espaço anterior, o exílio de Flusser é novamente mencionado, sendo também evidenciado o seu interesse pelo vento, deuses e a mitologia, a areia do deserto e a observação partindo do acúmulo de grãos, tão importantes para a criação de sua teoria sobre os pixels da imagem eletrônica.

Na parte externa da unidade, da fachada para o jardim, hospedaram os desenhos de Louis Bec para o livro Vampyroteuthis Infernalis. Um painel identificava os desenhos e apresentava um compilado das características que foram abordadas por Flusser na publicação.

Para o espectador que caminhava na parte externa, o muro do deck encontrava-se coberto de $Q R$ Codes, aplicados de modo sinuoso na parede. A instalação e o módulo "O concreto e a areia ou o mundo das não-coisas”, de Renato Sass, era composta por cerca de 70 links de internet codificados em barras $Q R$. Ao dirigir o celular com um leitor de $Q R$ Code ativado, um link redirecionava para sites externos, como para a pintura Saturno devorando seu filho (1819-1823), de Francisco Goya. No texto curatorial, a ênfase de que "uma das consequências da linha e do pensamento que se esconde por detrás da linha é abstração. A abstração é capaz de reduzir a espacialidade de um objeto ao transformar a sua tridimensionalidade em unidimensionalidade.”

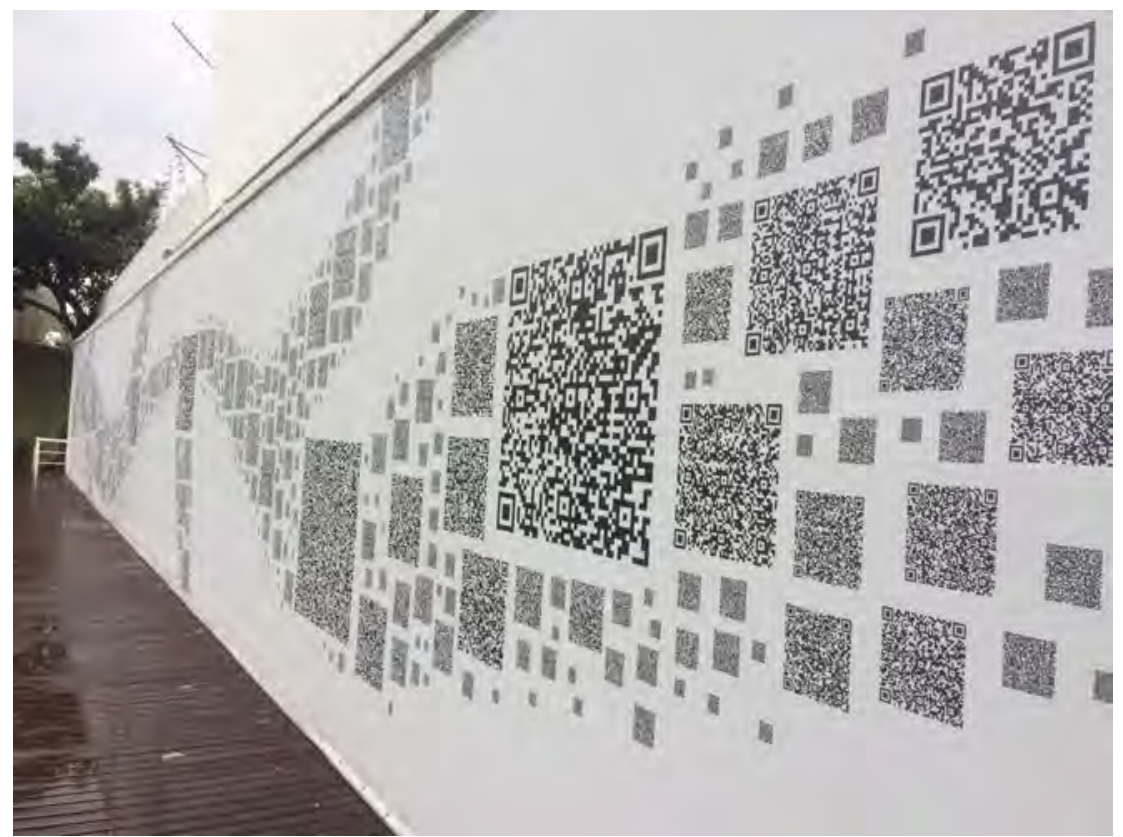


Figura 2. A parede de QR Codes. Crédito: Cássia Hosni.

Na parte externa foi instalada o módulo-contêiner, a instalação sonoro-visual “Casa furada”, realizada por Rodrigo Gontijo e Simon Fernandes. As paredes do contêiner foram compostas por muitos espelhos de interruptores de tomada, nos quais sons eram emitidos. Em uma das paredes, uma câmera mirava o espectador e projetava no televisor a sua frente. A instalação faz referência a terceira grande catástrofe, na qual após a hominização, a civilização e a domesticação, o ser humano retorna ao nomadismo porque "nossas habitações tornaram-se inóspitas e inabitáveis. O lugar onde acreditávamos estar protegidos, agora perfurado, é invadido pelo vento hostil das informações".

O módulo "Celeiro das ideias", localizado no galpão externo, faz referência aos Seminários Internacionais do Celeiro, realizados na pequena cidade alemã de Weiler, e dos quais Flusser participou. Na exposição, o lugar foi ambientado com madeira e feno, concentrando fotografias, vídeos, matérias de jornal escritas pelo filósofo e também outros segmentos como vídeos de artistas e correspondências entre Flusser e outros pensadores e artistas, a sua relação com a Bienal de São Paulo, o projeto A Casa Cor, entre outros.

Na parede entre as galerias, foi montado o módulo de "O gesto e a escrita”. Formado por letras, símbolos e linhas, o espectador era convidado para formar agrupamentos de letras ou palavras na parede. Enfatizando a aproximação de que o gesto do espectador criaria linhas, em consonância com o conceito do pensamento linear e histórico.

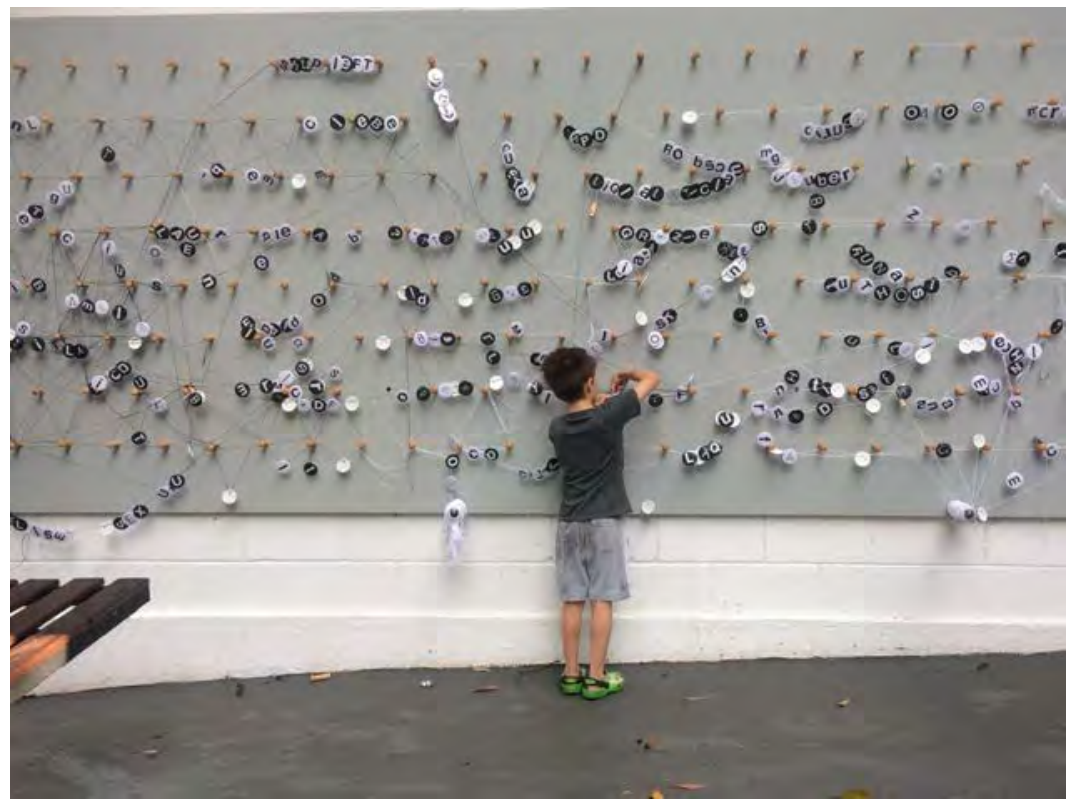

Figura 3. Parede de letras e palavras. Crédito: Cássia Hosni

A “Seção dos artistas” fazia referência à escrita de Flusser para os suplementos culturais dos jornais O Estado de S. Paulo e a Folha de São Paulo. A galeria mostrava sua relação com os artistas e continha 22 obras e 19 textos expostos na mesa de luz, dentre eles Gabriel Borba, Mira Schendel, Niobe Xandó e outros artistas notáveis.

De apelo sensorial, uma das últimas salas era o ambiente chamado "Caixa preta”, em referência ao livro Filosofia da caixa preta - Ensaios para uma futura filosofia da fotografia. A sala era composta por um ambiente totalmente escuro, onde o espectador caminhava com as mãos na parede, tateando diversos aparelhos e objetos, como antigas câmeras fotográficas, aparelhos como fax e rolos de filme fotográfico. 


\section{O pensamento filosófico no espaço expositivo}

No Brasil, o livro Filosofia da caixa preta foi uma das obras mais conhecidas do filósofo por estudantes e críticos que se interessavam pela questão arte e comunicação na década de 1980. Originalmente publicada em 1983 na Alemanha, recebeu o título de Por uma filosofia da Fotografia (Fur eine Philosophie der Fotografie), na qual obteve tradução similar para outras línguas. Já a publicação brasileira teve o título alterado para a Filosofia da caixa preta e foi lançada em São Paulo em 1984, já com alterações significativas do original e inserindo os debates e as argumentações que ocorreram no período que a obra foi inicialmente lançada.

Arlindo Machado (1999) menciona que a versão brasileira teve o prefácio refeito, a inserção de novos termos no glossário e capítulos inteiros reescritos, sendo que "para ser realmente fiel ao pensamento de Flusser, a versão em língua portuguesa (e não a alemã) é que deveria ser tomada como o texto definitivo da Philosofie e, por consequência, ela é que deveria estar sendo utilizada como base para a tradução a outras línguas” (1999, p. 133).

Desse modo, é interessante observar que sua obra mais conhecida tenha sido reformulada em alguns aspectos para a edição brasileira. Flusser, em muitas de suas cartas, sentia uma carência na interlocução dos debates filosóficos no Brasil, algo que foi apontado no prefácio de Filosofia, "Submeto-o, pois, à apreciação do público brasileiro. Faça-o com esperança e com receio. Esperança, porque, ao contrário dos demais públicos que me lêem, sinto saber para quem estou falando; receio, por desconfiar da possibilidade de não encontrar reação crítica” (Flusser, 2011, p.14). Talvez por essa e inúmeras outras razões seja interessante reavivar o pensamento flusseriano, trazendo questões até então ainda não debatidas.

Propor o conceito da "escada da abstração" para a exposição, na qual cada degrau dessa escada significa uma perda espacial, certamente é um desafio ao pensar em imagens e suas formas de representação. A filosofia de Flusser trata da perda da tridimensionalidade para a bidimensionalidade das imagens e a consequente passagem para a escrita linear e o funcionamento dos aparelhos que produzem imagens técnicas. Além disso, outros conceitos como o gesto e a escrita, dentre outros temas foram expostos de modo que o público geral tomasse conhecimento da importância e originalidade da obra de Flusser, elencando os modos de produção da imagem contemporânea.

Embora a melhor forma de compreensão do pensamento de Flusser ainda esteja em suas publicações textuais, a exposição foi um esforço em trazer importantes discussões filosóficas para o espaço. As obras artísticas, como a parede de $Q R$ code, e os eventos paralelos, como as performances que trouxeram realidade virtual, fizeram uma atualização necessária, principalmente no que se refere a quanto o filósofo antecipou as questões diante da imaterialidade das imagens e das suas relações na sociedade.

\section{Referências}

Baitello Junior, N. (2005). Vilém Flusser e a Terceira Catástrofe do Homem ou as Dores do Espaço, a Fotografia e o Vento. Flusser Studies 03. Recuperado de http://www.flusserstudies.net/sites/www.flusserstudies.net/files/media/attachments/terceiracatastrofe-homem.pdf

Bernardo, G.; Mendes, R. (Ed.). (1999). Vilém Flusser no Brasil. Rio de Janeiro: Relume Dumará.

Flusser, V. (2011). Filosofia da caixa preta: ensaios para uma futura filosofia da fotografia. São Paulo: Annablume.

Machado, A. (1999). Atualidade do pensamento de Flusser. En Bernardo, G.; Mendes, R. (Ed.). (1999). Vilém Flusser no Brasil. Rio de Janeiro: Relume Dumará. 